\title{
Human Resource Management, Performance Management and Employee Performance Appraisal by SME Managers in Kosovo
}

Submitted 25/06/20, $1^{\text {st }}$ revision 28/07/20, $2^{\text {nd }}$ revision 22/08/20, accepted 30/09/20

\begin{abstract}
Alberta Tahiri ${ }^{1}$, Idriz Kovaçi ${ }^{2}$, Avni Krasniqi ${ }^{3}$
Abstract:

Purpose: This paper aims to provide a theoretical approach to the importance of Human Resource Management. We know that human resources are a functional department within enterprises, and well-done employee performance management is a key element for enterprises' success.

Design/Methodology/Approach: This study presents primary data collected through a structured questionnaire addressed to the managers of 50 small and medium enterprises in Kosovo, mainly in the country's largest cities. The questionnaire enabled us to obtain information on how much employee performance affects enterprise productivity and what employee performance appraisal system managers use to know the impact of performance on productivity.

Findings: The findings, after analyzing the data, show that organizational productivity depends a lot on employee performance. Also, the most commonly used system to appraisal employee performance in Kosovo enterprises is the control system.

Practical Implications: This study provides a clear understanding of human resource management and its importance in the enterprise, always emphasizing that human resources are among the main sources for enterprises' operation.

Originality/Value: The research paper is based on the original direct data from the enterprises taken as a research sample, which undoubtedly represents a direct observation of the case in question.
\end{abstract}

Keywords: Human resource management, performance, performance management, performance appraisal.

JEL code: $M 12$.

Paper type: Research article.

ISSN: 2241-4754, H index 10, Q3.

\footnotetext{
${ }^{1}$ Corresponding author, University of Applied Sciences in Ferizaj, Faculty of Tourism and Environment, Department of Tourism and Hotel Management, Ferizaj, Kosovo, alberta.tahiri@ushaf.net;

${ }^{2}$ University of Applied Sciences in Ferizaj, Faculty of Tourism and Environment, Department of Tourism and Hotel Management, Ferizaj, Kosovo, idriz.kovaci@ ushaf.net;

${ }^{3}$ PhD (C) at State University "St. KlimentOhridski", Bitola, Faculty of Tourism and Hospitality, Republic of North Macedonia, avnia2002@hotmail.com;
} 


\section{Introduction}

Our society would not exist as we know it today, nor would it evolve with these parameters in the presence of managers who run its organizations. Thus, P. Drucker pointed out that effective management is perhaps the main source of developed countries and the most indispensable source for their further development. All organizations, small or large, private or public, profit-oriented or not, regardless of the area in which they operate, have one thing in common: the need to be managed. To achieve the ultimate goal, each of them engages a range of human, material, and financial resources (Tahiri and Kovaçi, 2017).

For more than a century now, human resource management has evolved and developed into different areas as a discipline and practice in managing people in an organization. These disciplines and practices have gone through trial and error, theory-building, and testing of various concepts by practicing managers and academics. The underlying forces behind the evolution and development of human resource management have been (and still are) mainly environmental, and the quest for better ways of acquiring and utilizing labor. The changing organizational environment in the marketplace pushed managers to improve efficiency in the production and service delivery processes by increasing their ability to use people management's best practices at the time. That is employee management techniques or methods that would improve production, reduce service delivery costs, and at the same time, ensure the sustained availability of competent staff in the organization (Itika, 2011).

Three decades ago, the idea that HRM practices could be treated as an integrated system was not yet well established. Instead, each functional specialty of HRM existed within its own silo. In general, at that time, it was common for HRM professionals working within each functional specialty to make choices about the design of practices without fully considering interdependencies between functional areas. At that time, the focus of HRM professionals was ensuring that employees had the technical skills and knowledge required for specific jobs, and little attention was paid to the role behaviors that were required from all employees in order to successfully implement a particular competitive strategy (Schuler and Jackson, 2014). Starting in the late 1970s and early 1980s, human resource management (HRM) professionals and academics started to more actively consider how their work could contribute to the effectiveness (success) of their organizations (Jackson et al., 2014).

\section{Literature Review}

\subsection{Human Resource Management}

Human resource management (HRM), as a key player in the creation and development of a highly productive workforce, lies in the center of the debate on the 
competitiveness of businesses. Practices that promote employee motivation and effort, knowledge, skills, abilities, and opportunities for employee contribution generate favorable conditions for developing resources and capabilities that create value for organizations, contributing to their performance and the emergence of sustained competitive advantages. This set of practices has been called, among other denominations, high-performance work systems (Brito and Oliveira, 2016).

For an organization or institution to realize its goals, it must have the resources it needs and use them effectively. Resources available to a manager are human, financial, physical, and information. Human resource departments typically include individuals with a variety of knowledge, skills, and abilities that are expected to perform work activities to contribute to achieving the organization's objectives. Human resource management is resource-focused, focused primarily on management needs to provide and develop human resources (Kutllovci, 2004). The process of planning personnel needs, organizing, training, developing, and advancing staff is called human resource management (Luthans and Hodgetts, 1992; Son and Noja, 2013; Caran and Noja, 2015).

According to Howard Schultz, employees can make or break the company. If a customer has a positive interaction with an employee, the customer will come back. If an encounter is negative, the customer is probably gone for good. Attracting talented employees involves recruiting qualified candidates and selecting those who best fit the organization's needs. Development encompasses both new-employee orientation and the training and development of current workers. Retaining good employees means motivating them to excel, appraising their performance, compensating them appropriately, and doing what is possible to keep them (Skripak, 2018).

\subsection{The Evolution and Development of Human Resource Management}

Human resource management, as a practice, happens wherever there is more than one person. Managing people in an organizational setting is well documented throughout the history of humanity. Organizational structures evolved, leadership emerged or was formed, roles and responsibilities were assigned to people, accountability systems were laid down, and rewards and punishments were also provided. In this regard, the division of labor, specialization, and accountability were systematically organized to achieve a specific purpose (Itika, 2011).

The origin of HRM as a school of thought is sought in the early 1970s and the "Human Capital Theory" developments. According to this theory, it was argued that it is more appropriate to view human resources as wealth (as a resource) as the opposite of cost. This view remained in the literature during the 1970s but received more support in the early 1980s (Llaci and Koli, 2001). 
Figure 1. Stages in the evolution and development of human resource management

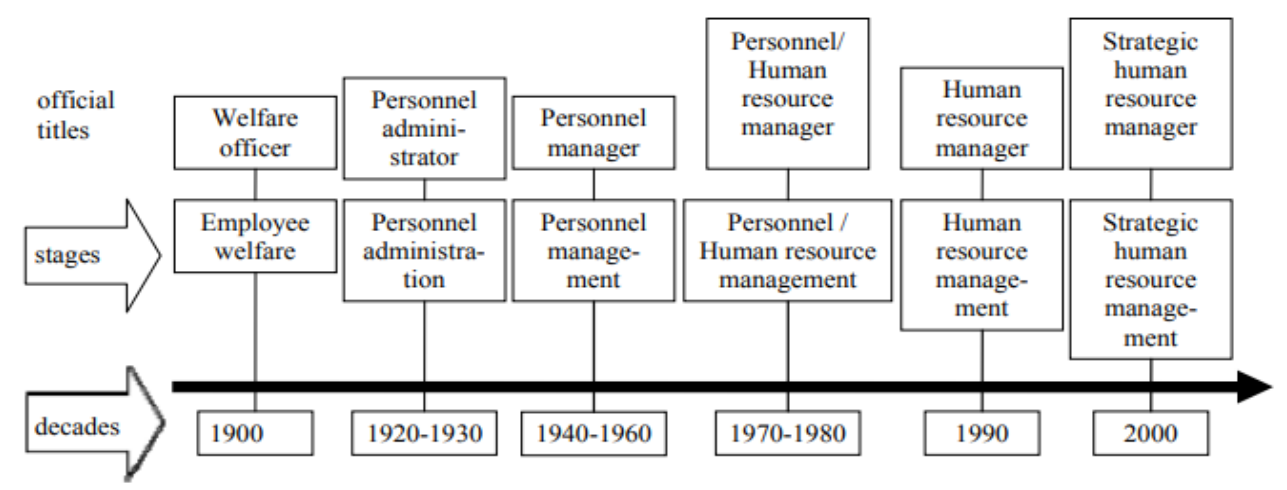

Source: Itika, S.J., (2011). Fundamentals of Human Resource Management: Emerging experiences from Africa, African Studies Centre, University of Groningen, Mzumbe University.

\subsection{Strategic Human Resource Management}

The literature on strategic human resources management is based on two fundamental principles. The first concerns the strategic importance of human resources, their competencies, and behaviors, while the second refers to human resource management practices in developing these resources. Research on SHRM considers HR systems as a whole and their impact on the organization, as opposed to the traditional perspective, which assesses HR practices separately and considers their impact on individual performance. This movement toward a macro or systemic vision was due to greater clarity regarding the impact of the human resources function on organizational results. Such an approach also reflects the understanding that, in order to be more effective, HR policies and practices must be congruent with each other (horizontal alignment) and aim to achieve the strategic goals of the organization (vertical alignment) (Brito and Oliveira, 2016).

Strategic human resource management research increasingly focuses on human resource (HR) systems' performance effects rather than individual HR practices. Researchers tend to agree that the focus should be on systems because employees are simultaneously exposed to an interrelated set of HR practices rather than single practices one at a time, and the effects of HR practices are likely to depend on the other practices within the system. Research consistently shows a positive association between (broad) HR systems and performance, and the idea of complementarities or synergies between practices in an HR system is widely accepted as the conceptual logic behind the effectiveness of HR systems. Despite this agreement, the extent to which this fundamental assumption in the field of interactions and synergy in the system is unclear. In other words, our understanding of the "systems" element of HR systems seems more nascent than one might expect, given the sizable body of literature on HR systems (Boon et al., 2019). 
Strategic HRM is an approach that defines how the organization's goals will be achieved through people using HR strategies and integrated HR policies and practices. Strategic HRM is underpinned by three concepts: resource-based view, strategic fit, and strategic flexibility (Armstrong, 2008).

\subsection{Performance Management}

Performance management can be defined as a systematic process for improving organizational performance by developing individuals' and teams' performance. It means getting better results by understanding and managing performance within an agreed framework of planned goals, standards, and competency requirements. Processes exist to establish a shared understanding of what is to be achieved and manage and develop people to increase the probability that it will be achieved in the short and longer-term. It focuses people on doing the right things by clarifying their goals. It is owned and driven by line management (Armstrong, 2006):

Performance management is a "continuous process of identifying, measuring, and developing individuals' and teams' performance and aligning performance with the organization's strategic goals" (Smither and London, 2009). Performance management is a planned process of which the primary elements are (Armstrong, 2006):

- Agreement,

- Measurement,

- Feedback,

- Positive reinforcement and

- Dialogue.

Five issues need to be considered to obtain a full understanding of performance management (Armstrong, 2006):

- The meaning of performance,

- The significance of values,

- The meaning of alignment,

- Managing expectations,

- The significance of discretionary behavior.

Performance Management System (PMS) is defined as "a strategic and integrated approach of conveying continued success to institutions by developing the people in a way that improves group and personal performance." These systems provide a continuous and integrated approach for managing and rewarding performance. As already developed and implemented performance, related pay and appraisal systems were failing to deliver the results according to the expectations of management, an increasing number of profit and non-profit organizations are turning towards PMS 
for their organizations in order to achieve better results and better psychosomatic outputs (Qureshi et al., 2010).

\subsection{Performance Appraisal}

One of the most important issues in human resource management is the appraisal of employees' performance (staff, managers). This is an organizational and managerial issue. It is an organizational issue because it does planning, organizing, leading, directing, and controlling appraisal activities to make the appraisal more efficient. It is a managerial issue due to managers' involvement in the appraisal, which aims to advance the quantitative and qualitative performance of the work and orient all activities towards achieving the goal. These two issues must be harmonized (Kutllovci, 2004). The notion of performance means the employee's knowledge and skills to understand and perform the job effectively, the knowledge in analyzing and synthesizing issues, and the experience and other special characteristics that a job requires (Leopold et al., 1999).

Performance appraisals are used to assess an employee's performance and to communicate that performance to the employee. Performance appraisal is called employee rating, employee evaluation, performance review, performance evaluation, or results appraisal. Performance appraisals are widely used to administer wages and salaries, give performance feedback, and identify individual employee strengths and weaknesses. Poorly done performance appraisals lead to disappointing results for all concerned. However, having no formal performance appraisal done may limit an employer's options regarding discipline and dismissal. Performance appraisals can answer whether the employer acted fairly or how the employer actually knew that the employee's performance did not meet standards. Even though an employer technically may not need a reason to terminate an employee, as a practical matter, appraisals can justify such actions should they become necessary. Employees also benefit if appraisals help them determine how they can improve their performance, even after a positive appraisal (Mathis and Jackson, 2008).

A performance appraisal is known by other terms like employee appraisal, performance review. Looked at performance appraisal as a method by which an employee's job performance is measured in terms of quality, quantity, cost, behavior, and time. He further explained that it is conducted by self, peers, seniors, and junior. However, generally, in the formal method, it is conducted by the immediate manager or supervisor under whom the person is directly working. A performance appraisal is a part of measuring, comparing, finding, guiding, correcting, and managing the employees (Sabiu et al., 2019).

Traditionally, the performance appraisal has been widely used to evaluate employee performance, set goals for future performances, and identify areas of professional development required by the individual (DeNisi and Pritchard, 2006; Manasa and Reddy, 2009). Typically, a formal appraisal process will be conducted for an 
employee at a minimum of twice per year. DeNisi and Pritchard (2006) state: "The goal of the performance management process is performance improvement, initially at the level of the individual employee, and ultimately at the level of the organization. The ultimate goal of performance appraisal should be to provide information that will best enable managers to improve employee performance. Thus, ideally, the performance appraisal provides information to help managers manage in such a way that employee (and organizational) performance improves".

Ultimately, problematic issues relating to performance appraisals arise due to two main factors: (a) the performance appraisal process is not being implemented correctly, or (b) the process is not suitable to how the organization operates. The challenges that arise from these issues are (O'Boyle, 2013):

- Advocates (both practitioners and academics) of Total Quality Management (TQM) claim that performance appraisals are unnecessary in most organizations and that TQM will ensure a high level of performance within all aspects of the organization.

- It has been noted that individual employees often have negative perceptions about the performance appraisal process.

- The rating system used to evaluate employee performance must be appropriate and applied to all employees of a similar level within the organization.

- If the performance appraisal process is not conducted appropriately and professionally, the organization may be subject to legal issues that could arise.

- For organizations that use a performance-based pay scheme, the performance appraisal is a significant factor in determining how much of the bonus an employee is entitled to.

\section{Research Methodology}

This paper's methodology is based on the study of the literature, which deals mainly with human resource management, performance management, and performance appraisal of employees in the enterprise. The sources used for this paper's compilation are books, relevant scientific papers, and primary data. This paper is based on the research of a sample of 50 small and medium enterprises in Kosovo. Data for this research related to productivity, performance, and employee performance appraisal, were collected from the questionnaire addressed to the managers of these 50 surveyed SMEs. In this way, the data presented are the primary data obtained directly from the enterprises.

\section{Results}

Success appraisal can be both an appraisal of employee success and an appraisal of manager success. Employee appraisal success is based on the following requirements: 
- To determine the necessary bases and measures for giving incentives, advances (gradations), changing the organizational hierarchical position, etc.

- To identify training needs and

- To make known among the employees, the degree of success in terms of the possibility realized towards the required one.

Determining or evaluating employee success is the basic requirement in a manager's job. The manager must first determine the work that the employee has to do. This usually determines the standards of success, both in quantity and quality. When setting the standards, the assessment's necessary data must be provided (Ramosaj, 2013).

\section{Table 1. The organizational productivity}

How much do you think that the organizational productivity depends on the employee performance?

\begin{tabular}{|l|l|l|l|l|}
\hline Alternatives/options & Frequency & Percent & $\begin{array}{l}\text { Valid } \\
\text { Percent }\end{array}$ & $\begin{array}{l}\text { Cumulative } \\
\text { Percent }\end{array}$ \\
\hline Not at all & 0 & $0 \%$ & $0 \%$ & $0 \%$ \\
\hline Slightly & 2 & $4 \%$ & $4 \%$ & $4 \%$ \\
\hline Averagely & 3 & $6 \%$ & $6 \%$ & $10 \%$ \\
\hline Enough & 12 & $24 \%$ & $24 \%$ & $34 \%$ \\
\hline A lot & 33 & $66 \%$ & $66 \%$ & $100 \%$ \\
\hline Total & $\mathbf{5 0}$ & $\mathbf{1 0 0 \%}$ & $\mathbf{1 0 0 \%}$ & \\
\hline
\end{tabular}

Source: SPSS 23 output, compiled by authors.

Table 1 contains data regarding how the organizational productivity depends on the employee's performance. These data are given in the form of frequency and percentage of how responses were scored on a Likert scale. As is shown, most of the answers are focused on "enough" (24\%) and "a lot" (66\%) options, which means that employee's performance has an important role in the success of organizations.

Figure 2. The organizational productivity

How much do you think that the organizational productivity depends on the employee performance?

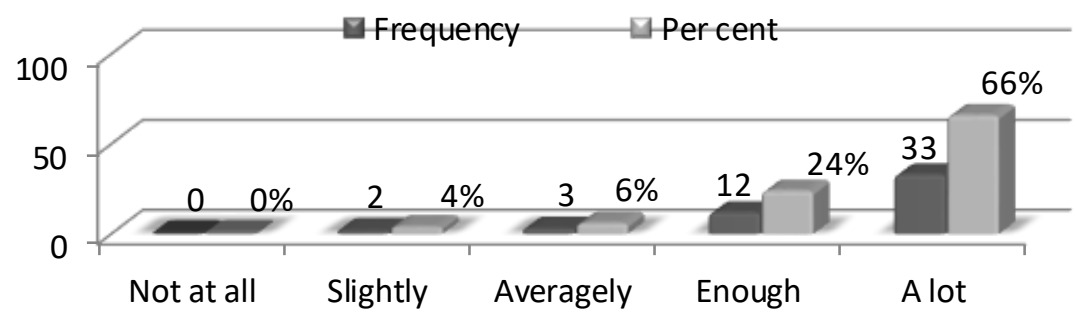

Source: Compiled by authors. 
Figure 2 shows graphically the percentage that resulted in asking managers how much they think that the organizational productivity depends on the employee performance. And it turns out that organizational productivity depends a lot on employee performance and we can say that if employees have good performance then the organizational productivity won't lack.

Table 2. Performance appraisal system

Does your enterprise have a performance appraisal system for employees?

\begin{tabular}{|l|l|l|l|l|}
\hline Alternatives/options & Frequency & Percent & Valid Percent & $\begin{array}{l}\text { Cumulative } \\
\text { Percent }\end{array}$ \\
\hline Yes & 48 & $96 \%$ & $96 \%$ & $96 \%$ \\
\hline No & 2 & $4 \%$ & $4 \%$ & $100 \%$ \\
\hline Total & $\mathbf{5 0}$ & $\mathbf{1 0 0 \%}$ & $\mathbf{1 0 0 \%}$ & \\
\hline
\end{tabular}

Source: SPSS 23 output, compiled by authors.

Table 2 contains regarding the question whether an enterprise has an employee's performance appraisal system. Managers had to answer yes or no to this question. Figure 3 presents the answers obtained. Only a small number of enterprises does not apply a performance appraisal system $(4 \%)$. These enterprises need to make a change in this regard.

Figure 3. Performance appraisal system

\section{Does your enterprise have a performance appraisal sys}

Source: Compiled by authors.

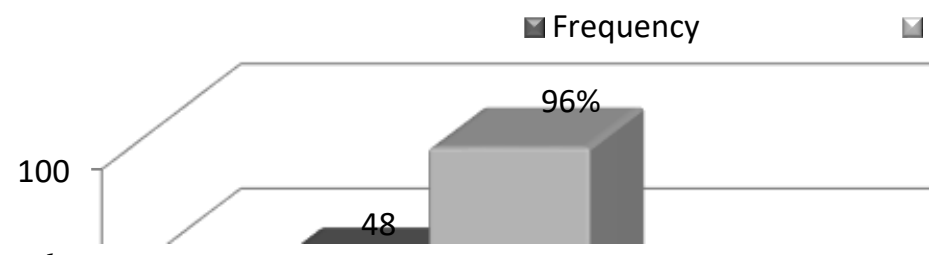

Based on Figure $296 \%$ of small and medium enterprises in Kosovo apply a performance appraisal system for employees and only $4 \%$ do not apply such a system.

\section{Conclusions}

From the above theoretical elaboration and research, we can conclude that human resource management is an essential discipline related to how enterprises' staff works. So, it deals with everything in the interests of employees and the interests of enterprises to hire qualified and trained employees who do the job effectively and 
efficiently. To be effective at work, every enterprise must work in terms of performance management of its staff. Also, performance appraisal is one of the key elements for enterprise success. Enterprises should have employee performance appraisal systems to know who is doing the job properly and who is not, and also based on performance appraisal, bonuses should also be given to employees. The research sample has shown that enterprises in Kosovo practice several performance appraisals systems such as:

- $\quad$ MBO (Management by Objectives),

- $\quad$ ABR (Appraisal by Results)

- Control system.

The MBO is a strategic management model that aims to improve an organization's performance by clearly defining the objectives agreed upon by management and employees. About $17 \%$ of the surveyed enterprises use this appraisal system.

$\mathrm{ABR}$ is a technique that can help improve the manager's and the whole organization's success, showing the positive aspects of this technique. However, in our research, we are based on obtaining clarifications on applying this technique in evaluating the employees of the enterprise and how it also influences their motivation with its implementation, which increases the effectiveness at the organization level. This technique is used by about $21 \%$ of surveyed enterprises.

Different enterprises apply the control system in different ways. Enterprises apply the employee control system every 4 weeks or less. About $62 \%$ of the enterprises use the control system, one of the most widely spread system in Kosovo.

Great importance in these enterprises is also given to the way employees are motivated to perform better. Thus, employee performance is influenced by monetary benefits, opportunities for promotion, performance appraisal, and other elements depending on which enterprise apply.

\section{References:}

Armstrong, M. 2006. A Handbook of Human Resource Management Practice. Kogan Page, London and Philadelphia.

Armstrong, M. 2008. Strategic Human Resource Management: A Guide to Action. Kogan Page, London and Philadelphia.

Boon, C., Den Hartog, D.N., Lepak, D. 2019. A systematic review of human resource management systems and their measurement. Journal of Management, Sage Publishing, 45(6), 2498-2537.

Brito, R.P., Oliveira, L.B. 2016. The relationship between human resource management and organizational performance. Brazilian Business Review, 13(3), 90-110.

Caran, M., Noja, G.G. 2015. Employee benefits in multinational firms: Empirical evidence for Romania and Serbia. Megatrend revija, 12(2), 155-170.

DeNisi, A.S., Pritchard, R.D. 2006. Performance Appraisal, Performance Management and 
improving individual performance: A motivational framework. Management and Organization Review, 2(2), 253-277.

Itika, S.J. 2011. Fundamentals of Human Resource Management: Emerging experiences from Africa, African Studies Centre, University of Groningen, Mzumbe University.

Jackson, S.E., Schuler, R.S., Jiang, K. 2014. Strategic HRM: a review and framework. Academy of Management Annuals, 8(1), 1-56.

Kutllovci, A.E. 2004. Human Resource Managemnet. University of Prishtina, Economic Faculty, Prishtina.

Leopold, J., Harris, L., Watson, T. 1999. Strategic Human Resourcing: Principles, Perspectives and Practices. Sage Publication, London.

Luthans, F., Hodgetts, R. 1992. Business. New York.

Llaci, Sh., Koli, Z. 2001. Human Resource Management. Tirana.

Manasa, K., Reddy, N. 2009. Role of Training in improving performance. The IUP Journal of Soft Skills, 3, 72-80.

Mathis, L.R., Jackson, H,J. 2008. Human Resource Management. Thomson South-Western, USA.

O’Boyle, I. 2013. Individual performance management: A review of current practices. Asia-Pacific Management and Business Application, 1(3), 157-170.

Qureshi, J.A., Shahjehan, A., Rehman, Z., Afsar, B. 2010. Performance management systems: A comparative analysis. African Journal of Business Management, 4(9), 1856-1862.

Ramosaj, B. 2013. Management, Fundamentals of Management. University of Prishtina, Prishtina.

Sabiu, M.S., Ringim, K.J., Mei, T.S., Joarder, M. 2019. Relationship between human resource management practices, ethical climates and organizational performance, the missing link. PSU Research Review, Emerald Publishing Limited, 3(1), 50-69.

Schuler, R., Jackson, S.E. 2014. Human resource management and organizational effectiveness: yesterday and today. Journal of Organizational Effectiveness: People and Performance, Emerald Group Publishing Limited, 1(1), 35-55.

Skripak, J.S. 2018. Fundamentals of Business. VT Publishing, Blacksburg, Virginia.

Smither, J., London, M. 2009. Performance Management, Putting Research into Action. Jossey-Bass, A Wiley Imprint, San Francisco, California.

Son, L., Noja, G.G. 2013. The role of the human capital and investment in human capital within the sustainable socio-economic development. How labour force migration affects competitiveness? Theoretical and Applied Economics, 18(10(587)), 111 126.

Tahiri, A., Kovaçi, I. 2017. Management in Tourism: Theoritical Approach, Research Centre, Peja. 